\title{
EL DERECHO A LA PROPIA IMAGEN EN SU DIMENSIÓN SUBJETIVA Y LOS CÓDIGOS DE INDUMENTARIA LABORAL
}

ESTHER GONZÁLEZ-HERNÁNDEZ 


\section{SUMARIO}

1. INTRODUCCIÓN, 2. LA CARACTERIZACIÓN CLÁSICA DEL DERECHO A LA PROPIA IMAGEN. 2.1. Imagen y «propia» imagen: diferencias conceptuales, 2.2. La prohibición de la reproducción de la imagen no consentida., 3. EL DERECHO A LA PROPIA IMAGEN Y LOS «CÓDIGOS DE INDUMENTARIA LABORAL»: ¿VULNERACIÓN DEL ART. 14 Ó DEL 18.1 CE?. 3.1. El estado de la cuestión en la jurisprudencia. 3.2. Imagen y proceso de selección. 3.3. Análisis desde la perspectiva de género. 4. CONCLUSIONES. 


\title{
EL DERECHO A LA PROPIA IMAGEN EN SU DIMENSIÓN SUBJETIVA Y LOS CÓDIGOS DE INDUMENTARIA LABORAL
}

\author{
ESTHER GONZÁLEZ-HERNÁNDEZ ${ }^{1}$ \\ Universidad Rey Juan Carlos
}

\section{INTRODUCCIÓN}

Resulta, más que curioso, paradigmático que uno de los tres derechos a los que se refiere el artículo 18.1 CE, de una forma ciertamente telegráfica, fuese el que, a priori, pareciese que suscitaría menos conflictividad. Sin embargo, podría suponer en el futuro situaciones dignas de atención por nuestro Tribunal Constitucional.

Desde hace unos 50 años, en que como consecuencia del auge de la fotografía, el mundo actual es el «vertiginoso mundo de las imágenes» era necesario proteger al ciudadano de la reproducción de su imagen cuando no fuera consentida. Quizás por ello se menciona en último lugar, como si careciese de importancia, amén de la escasez de estudios globales altamente especializados, que, por lo general, obedece más a consideraciones de cierto clasicismo en su tratamiento.

Con esto, pretendo remarcar que, hasta la fecha la jurisprudencia de nuestro Alto Tribunal se ha limitado al análisis de su versión clásica y objetiva, esto es, la propia del siglo pasado en que la fotografía y la imagen en movimiento se desarrolló de tal modo que pareció imprescindible exigir la prestación de consentimiento para la reproducción de esta imagen, máxime si era con una finalidad de lucro o incremento patrimonial.

Obviamente, esta dimensión tiene su importancia (lo vamos a comprobar en estas páginas), más en los tiempos que vivimos. A nadie se le escapará que la proliferación de redes sociales de todo tipo son un campo abonado para multiplicación de este tipo

1 Profesora Titular de Derecho Constitucional. Departamento de Derecho Público I y Ciencia Política. Facultad de Ciencias Jurídicas y Sociales. Universidad Rey Juan Carlos. Edificio Departamental. Paseo de los Artilleros s/n. 28032. Madrid. Código orcid.org/0000-0001-7203-5032. Email: esther. gonzalez@urjc.es. 
de circunstancias. Hoy casi todo el mundo da por sentado que puede publicar en «sus» redes (cuando en realidad es «una red global») cualquier contenido y nadie se para a pensar en que ello puede suponer la conculcación de varios derechos se si muestra la imagen no consentida de una o varias personas en cualquier circunstancia, pero máxime si dicha imagen pudiera trasladar una percepción social. Así, se vulnerarían el derecho al honor y a la intimidad personal y familiar, incluso a la inviolabilidad del domicilio, ahora que abundan la publicación en redes de los «pantallazos» de las conexiones on-line de casas particulares.

Sin duda, esta es una vertiente importante y, sobre todo, objetivable. Sin embargo, ya existen y se desarrollarán a una velocidad inimaginable otras dimensiones del derecho a la propia imagen que permiten debatir sobre su dimensión subjetiva. Esta cuestión se puede analizar desde una doble perspectiva: la propia de la conflictividad respecto de los «códigos de indumentaria» laboral y, otra, aún más novedosas que, poco a poco, terminará siendo más frecuente y a lo que se tendrá que dar respuestas. Esta cuestión todavía no ha sido abordada por la jurisprudencia de nuestro Tribunal Constitucional, pero, a buen seguro, llegará y será objeto de amparo y admisión de la correspondiente demanda por vulneración de derechos dentro del supuesto de «especial trascendencia constitucional que exigiría la adaptación constitucional. Sin duda, estamos ante una cuestión compleja, porque lamentablemente «es uno de los derechos menos nítidos y, por consiguiente, más difíciles de delimitar»².

\section{LA CARACTERIZACIÓN CLÁSICA DEL DERECHO A LA PROPIA IMAGEN}

A principios del siglo xx, la opción clásica a la hora de regular el derecho a la propia imagen pasaba por considerarlo un «derechos de la personalidad», como consecuencia de la influencia de la doctrina alemana que defendía de su naturaleza jurídica de «bienes de la personalidad» ${ }^{3}$. A ello, se unió la configuración anglosajona del right to privacy, que lo entendía como una de tantas manifestaciones de la vida privada.

Por tanto, hasta ahora tanto la legislación como la jurisprudencia mayoritaria, incluso la Constitucional, habrían considerado el concepto de «imagen» en el sentido de reproducción, copia o representación bidimensional por fotografía, pintura, ilustración, representación cinematográfica en el cine, video y/o televisión y, a lo sumo, en tres dimensiones como puede ser una escultura o, incluso, una holografía. Al

2 PARDO FALCON, J. (1992). «Los derechos del artículo 18 de la Constitución española en la jurisprudencia del Tribunal Constitucional», REDC, núm. 34 (enero-abril), p.166.

3 Ibidem, p. 141. 
margen de esto, también hay otro sector que incide en su aspecto patrimonial, que, sin duda, en los tiempos que corren es relevante ${ }^{4}$.

Sea como fuere, nosotros apostamos por analizarlo también como un derecho vinculado a la dignidad de la persona, a su patrimonio moral, es decir, aquel espacio de libertad y, sobre todo, de autodeterminación de la propia apariencia. Pero en el momento de redacción de la actual Constitución española de 1978 eran pocos los textos constitucionales que reconocían el derecho a la propia imagen, menos aún como manifestación de la personalidad, a pesar de lo expresado en el art. $10 \mathrm{CE}$, que explicaremos con más detalle en las páginas ulteriores. Así por ejemplo el art. 26 de la Constitución portuguesa: «Todos tienen el derecho a la identidad personal, al desarrollo de su personalidad, a la capacidad civil, a la ciudadanía, a su buen nombre y reputación, a su imagen, a su expresión, a proteger la privacidad de su vida personal y familiar y a la protección legal contra cualquier forma de discriminación». También el art. 5. 10 de la brasileña: «10. Son inviolables la intimidad, la vida privada, el honor y la imagen de las personas...» y el 2-4 del texto peruano: «A las libertades de información, opinión, expresión y difusión del pensamiento mediante, la palabra oral o escrita o la imagen, por cualquier medio de comunicación social...».

A pesar de esto, es importante señalar la trascendencia que supuso el reconocimiento de este derecho por nuestra Carta Magna, pues hasta ese momento, la realidad jurídica sobre la utilización indiscriminada de la imagen en sus variadas vertientes solo se veía reflejada a nivel jurisprudencial ${ }^{5}$. Aunque es también justo recordar que «el reconocimiento expreso y autónomo de este derecho no se preveía en el anteproyecto — reservado únicamente al honor y la intimidad - sino que su inclusión fue consecuencia de las enmiendas número 716 y 779, propuestas por el Sr. Sancho Rof y Grupo Unión de Centro Democrático, que fueron aprobadas en el Congreso el 21 de julio de 1978 y remitidas al Senado, en que Camilo José Cela presentaría una enmienda de supresión» ${ }^{6}$ que no prosperó ${ }^{7}$, entre otros motivos porque el propio Código penal de 1973 ya se refería a «Los delitos y faltas que se cometan por medio de la imprenta, el grabado u otra forma mecánica de reproducción, radiodifusión u otro procedimiento que facilite la publicidad» (art. 12).

Lo cierto, es que en su conceptualización ha tenido mucho que ver el desarrollo de la fotografía y otros medios de reproducción audiovisual. Si bien, algunos sitúan su origen en el Derecho romano, en concreto en el «Jus imaginis como una forma de

\footnotetext{
4 Merece consulta: VENDRELL CERVANTES, C. (2014). El mercado de los derechos de imagen. El consentimiento o autorización para la intromisión en los derechos de la personalidad y la transmisión de derechos de imagen, Aranzadi, Navarra.

5 Véase la STS de 8 de marzo de 1974 o St. de la Audiencia provincial de Zaragoza de 9 de junio de 1967.

6 DE LAS HERAS VIVES, L. (2018). «El derecho a la propia imagen en España. Un análisis desde el derecho constitucional, civil y penal», Actualidad Jurídica Iberoamericana, IDIBE, núm. 8, feb. p. 437

Cela sostenía que la propia imagen es un concepto que sobra por impreciso y no aceptaba su entendimiento como derecho autónomo dado que lo conectaba o bien con la intimidad o el honor.
} 
derecho a la imagen. Esta institución consistió en el privilegio reconocido a la nobleza de exponer en el atrium de los palacios los retratos de sus antepasados que hubieren desempeñado magistraturas curules y que más tarde se extendió a la plebe por haberse hecho esos cargos accesibles a los miembros de esa clase» ${ }^{8}$. Es decir, consistía en la posibilidad de mantener en el atrium de sus domicilios y exponer en determinadas ceremonias (cortejos fúnebres y victorias de la familia) los retratos (bustos de mármol o de bronce, máscara de cera, estatuas) de los antepasados, es decir, que se ocupaba de determinar cuándo y cómo la imagen podría ser divulgada socialmente ${ }^{9}$. Sin embargo, esta explicación lo aleja de la protección patrimonial en la que se basa la concepción clásica actual. Es más ya en los siglos XVI y XVII se empezó a discutir la posibilidad de un derecho individual y autónomo de disposición sobre el propio cuerpo, y del que derivaría la facultad de disponer del reflejo del cuerpo, entendido como la imagen de la persona ${ }^{10}$.

Pero esta discusión se relega al olvido cuando empiezan a surgir métodos rudimentarios de reproducción ilimitada de la imagen a partir de 1841 por el invento del por Fox Talbot. Desde esta fecha se van superando los múltiples obstáculos y dificultades hasta que en 1935 Mannés y Godowsky consiguen unas imágenes en color de gran calidad y aparece en escena la empresa Kodak. Es en este momento, mediados del siglo $\mathrm{xx}$, el Derecho se ve obligado a dar una respuesta, primero a través del Derecho Civil y después del Derecho Constitucional. Hay que recordar el famoso caso de los herederos de Bismarck que se opusieron a la publicación de las fotografías de su cadáver, pues el tema en aquellas fechas se centraba, tanto a nivel jurisprudencial como constitucional, solo en el consentimiento para la reproducción de la persona afectada y se olvidaba su dimensión subjetiva. Primó, pues su dimensión objetiva y patrimonializable; opción perfectamente asentada a nivel jurisprudencial en Europa desde 1902 ya se afirmaba categóricamente que no se podía fotografiar a nadie sin su consentimiento, excepto en casos de profesión o notoriedad que suscitase un especial interés.

A nivel legal el derecho a la propia imagen en Europa ya estaba reconocido en el siglo XIX, que es el momento en que se pasa de los cuadros, bustos y esculturas en que el representado daba su consentimiento, al ser, normalmente, consecuencia de encargos de las clases adineradas (conocidos como «comitentes»), a otros procedimientos de representación de las imágenes donde no media consentimiento y si posible reproducción ilimitada. Por tanto, hasta que no llega la fotografía en el debate jurídico no entraba la protección de la imagen humana, mucho menos en el debate constitucional que Alzaga sitúa en la tardía fecha de 1976, vía Constitución

8 PERLA VELAOCHAGA, R. (1944). «El derecho a la propia imagen», UCP: Revista de la Facultad de Derecho, p. 35.

9 RODRIGUES DA CUNHA E CRUZ, M. A., (2009), «El concepto constitucional del derecho a la propia imagen en Portugal, España y Brasil», Araucaria: Revista Iberoamericana de Filosofía, Política, Humanidades y Relaciones Internacionales, Vol. 11, núm. 22, p. 19.

10 Ibídem, p. 20 
portuguesa que permitió que nuestra legislación civil y penal pudiese avanzar por la senda de los diferentes Códigos civiles como el italiano de 1942, el griego de 1946, el egipcio de 1948, el japonés del mismo año y el filipino de $1949^{11}$.

\subsection{Imagen y de «propia» imagen: diferencias conceptuales}

Para apoyar nuestra tesis vayamos a uno de los criterios generales interpretativos de la norma, quizás el más usado y el menos útil, el criterio literal que supone acudir al análisis terminológico de la palabra «imagen». Así, según la RAE por «imagen» (Del lat. imāgo, -ǐnis) debemos entender: f. Figura, representación, semejanza y apariencia de algo. Ahora bien, la Constitución española habla de «propia» imagen.

Si volvemos al diccionario de la RAE por «propio/a» hay que entender, al menos: «1. adj. Que pertenece de manera exclusiva a alguien. 2. adj. Característico, peculiar de cada persona o cosa». De tal modo que podría definirse como «el conjunto de rasgos que caracterizan ante la sociedad a una persona o entidad» $»^{12}$, es decir, una definición que podría equivaler a «perteneciente o relativo a alguien que tiene la facultad exclusiva de disponer de ello». Quizás por este tipo de consideraciones, hay autores que lo definen como «la representación sensible de la persona humana» ${ }^{13}$ y otros la califican como «primer elemento configurador de la individualidad» ${ }^{14}$.

Parece, pues, que desde la óptica del lenguaje y en el ámbito de la coloquialidad no debería circunscribirse exclusivamente a la reproducción no consentida de su imagen, pues se trataría de una versión demasiado rígida de la literalidad de la Constitución y demasiado apegada a una visión clásica y dimanante del Derecho Civil. Cierto es que literalmente no se puede hacer ninguna interpretación válida, dada la somerísima redacción que se limita al reconocimiento del derecho a la propia imagen, pero parece que, desde el punto de vista ontológico, la noción de derecho a (...) la «propia imagen» no puede circunscribirse al mero consentimiento o no a que se reproduzca un rostro facial, voz o nombre con finalidad comercial. Esta es una opción restrictiva y apartada de la realidad, sobre todo, laboral. Es más, aunque veladamente, el Tribunal Constitucional, en alguna ocasión, lo ha reconocido al definirla en los términos de «reproducción visible de la figura humana identificada o identificable, pues cabe extender el concepto a otras representaciones de la persona que la faciliten de modo evidente y no dubitativo o por aproximaciones o predisposiciones subjetivas, su recognoscibilidad» (STC 60/1998). He aquí la importancia de ampliar el ámbito de

11 AlZAGA VILlAAMIL. Ó. (2016). Comentario sistemático a la Constitución española de 1978, Marcial Pons, $2^{\mathrm{a}}$ ed, Barcelona, p. 160.

12 SÁNCHEZ GONZÁLEZ, Ma . P. (2017). Honor, intimidad y propia imagen, Jurua, Lisboa, p. 124.

PERLA VELAOCHAGA, op. cit., p. 33.

14 DE VERDA y BEAMONTE, J. R. (coord.) (2007). «El derecho a la propia imagen», Veinticinco años de Aplicación de la Ley Orgánica 1/1982, de 5 de mayo, de Protección Civil del Derecho al Honor, a la Intimidad Personal y Familiar y a la Propia Imagen, Cizur Menor. Edit. Thomson-Aranzadi, p. 145. 
análisis semántico no solo al término imagen, sino también al término "propia», como hemos explicado. Esta referencia a «propia» es lo que enlazaría este reconocimiento constitucional con el derecho a conformar la propia apariencia o identidad, al menos, en una vertiente subjetiva.

Por tanto, reconociendo, por supuesto, una dimensión patrimonial, también existe una dimensión, si no moral, (e, incluso, estética) conectada directamente con la dignidad de la persona, tal y como reconoce la STS 229/2009 que lo considera como un «derecho a la personalidad, esfera moral, relacionando con la dignidad humana»; sentencia a la que después se sumarán las STC 158/2009 y 201/2012.

Por tanto, Sánchez González ${ }^{15}$ termina por distinguir 5 vertientes del derecho a la propia imagen:

1. Posibilidad de impedir que se divulgue su propia imagen.

2. Facultad de evitar que la imagen se asocie a valores o conceptos peyorativos.

3. Facultad de impedir su captación no consentida por un tercero.

4. Derecho patrimonial que permite la facultad de controlar el uso comercial o publicitario de su imagen.

5. Facultad del individuo de configurar su aspecto externo, mantenerlo, modificarlo y determinar el modo de presentarse a los demás.

Esta última vertiente es, el concepto de «imagen somática» o exteriorización de determinada imagen corporal que te haga reconocible, identificable e individualizable, que abre un vastísimo campo a diferentes manifestaciones de este derecho en una sociedad tan cambiante, rápida y dominada por la imagen como la actual, pero también en otro tipo de cuestiones, por ejemplo, como la identidad de género.

Si bien es cierto que el bien jurídico que comentamos protege la persona humana de la representación gráfica de su aspecto físico externo, es decir, también lo es, como defiende, Rodrigues da Cunha e Cruz ${ }^{16}$, que «el sentido de la propia individualidad crea dos perspectivas en la configuración jurídica de tal derecho: de un lado, una exigencia de circunspección, de reserva, de exclusión, que garantiza la inviolabilidad personal y, de otro, establece la autonomía jurídica individual y la autodeterminación del individuo para proyectarse socialmente». Es decir, que este derecho tendría dos vertientes: la objetiva que consiste en la facultad de excluir la posibilidad de captación, reproducción, publicación de la imagen; y la positiva y subjetiva que permite a la persona que pueda determinar la imagen que quiere proyectar a los demás, sin más limitaciones que las objetivas y razonables según las circunstancias. En definitiva, la posibilidad de determinar su «propia» apariencia por diferentes detalles, esto su

15 SÁNCHEZ GONZÁLEZ, op. cit., pp. 126 y 127.

16 RODRIGUES DA CUNHA E CRUZ, op. cit., p. 24. 
vestimenta, peinado, etc. aplicados en las diferentes partes de su cuerpo, que lo individualiza respecto de otros.

Lo que aquí comentamos es el «derecho a la determinación de la imagen o de la «propia identidad» y a su reconocimiento visible y patente por el resto de las personas, siempre que dichas opciones no atenten contra el sustrato indisponible de la dignidad humana. Esta opción casa con la clásica explicación del derecho a la propia imagen, pues, en ambos casos el objeto de protección jurídica se determina «cuando se consigue percibir los rasgos particulares individualizadores de una persona humana, los que posibilitan la representación gráfica visible del aspecto físico externo de su figura» ${ }^{17}$. Así, parece tener cierto sustento la definición de la llamada «propia» imagen también que puede ser ampliada con la de «apariencia o aspecto físico de una persona», estando su fundamento, en el contenido esencial que es indisponible tanto para el legislador como para los órganos judiciales de todo derecho fundamental.

Ese contenido esencial no tiene porqué coincidir con la regulación legal del derecho, porque el derecho al que se refiere el art. 18.1 CE no es un derecho, como otros, de los llamados de «configuración legal», en los que el constituyente remite la definición del derecho a la ley. Es decir, su contenido esencial no es necesariamente idéntico a lo dispuesto, en la LO 1/1982, de protección civil del derecho al honor, a la intimidad personal y familiar y a la propia imagen ni a los arts. $197 \mathrm{y}$ ss. $\mathrm{CP}^{18}$.

Para dar con el contenido esencial del derecho contamos con la literalidad de la STC 11/1981, 8 de abril (Fj. 8) que explica los dos modos de determinar el contenido esencial de un derecho fundamental: «El primero es tratar de acudir a lo que se suele llamar la naturaleza jurídica o el modo de concebir o de configurar cada derecho. Según esta idea hay que tratar de establecer una relación entre el lenguaje que utilizan las disposiciones normativas y lo que algunos autores han llamado el metalenguaje o ideas generalizadas y convicciones generalmente admitidas entre los juristas, los jueces y, en general, los especialistas en Derecho [...] El segundo posible camino para definir el contenido esencial de un derecho consiste en tratar de buscar lo que una importante tradición ha llamado los intereses jurídicamente protegidos como núcleo y médula de los derechos subjetivos. Se puede entonces hablar de una esencialidad del contenido del derecho para hacer referencia a aquella parte del contenido del derecho que es absolutamente necesaria para que los intereses jurídicamente protegibles, que dan vida al derecho, resulten real, concreta y efectivamente protegidos (...) Los dos caminos propuestos para tratar de definir lo que puede entenderse por «contenido esencial» de un derecho subjetivo no son alternativos, ni menos todavía antitéticos, sino que, por el contrario, se pueden considerar como complementarios».

17 Ibidem, p. 26.

18 CUERDA RIEZU, A (2008). «El velo islámico y el derecho a la propia imagen», Parlamento y Constitución. Anuario, núm. 11, p. 253.

(C) UNED. Revista de Derecho Politico 
En definitiva, consistiría «en tratar de buscar lo que una importante tradición ha llamado los intereses jurídicamente protegidos como núcleo y médula de los derechos subjetivos. Se puede entonces hablar de una esencialidad del contenido del derecho para hacer referencia a aquella parte que es absolutamente necesaria para que los intereses jurídicamente protegibles, que dan vida al derecho, resulten real, concreta y efectivamente protegidos», sería, pues, una manifestación consustancial a la dignidad humana como la reproducción de una realidad innata e inmanente. Pues bien, lo más personal y consustancial a la persona no es la reproducción de su imagen sino la configuración y determinación de cómo quiere que se aprecien sus rasgos físicos. Esto es lo que la cultura popular o, cuanto menos, el lenguaje cotidiano entiende, pero también la «cultura jurídica». Así, como uno de tantos ejemplos, la STS 518/2012 expresa esta dimensión positiva del derecho a la propia imagen de atribución a su titular «del derecho a determinar la información gráfica generada por sus rasgos físicos personales». O la STS 929/2007, de 17 de septiembre, que en el ámbito civil, que el reconocimiento del cambio de sexo y su inscripción en el Registro Civil encuentra fundamento en el derecho a la propia imagen, dado que atribuiría a «su titular un derecho a determinar sus rasgos físicos personales y característicos». Es decir, que este derecho sería la posibilidad de una libre configuración de la apariencia física y a cambiarla a su antojo en cualquier momento, sin necesidad de justificación o autorización alguna. Esto, a sensu contrario, supone admitir la tesis que venimos defendiendo.

Sea como fuere, la jurisprudencia del Tribunal Constitucional, hasta la fecha prácticamente no se ha ocupado de esta dimensión del art. 18.1 in fine $\mathrm{CE} / 78$, sino en un sentido bien contrario, en la STC 170/1987, de 30 de octubre en que daba por válida la prohibición de llevar barba impuesta al barman de un hotel, porque la decisión personal sobre la apariencia física puede ser limitada en virtud de las relaciones laborales libremente asumidas mediante un contrato de trabajo, siempre que no superen los límites de la dignidad del ser humano. También en un sentido similar, pero en el sector público, la STC 120/1996, de 8 de julio, que ni siquiera entra en el fondo del derecho a la propia imagen de un agente de la policía municipal, que es sancionado por llevar el pelo largo, recogido incluso en una coleta.

Señala, sin embargo, Cuerda Riezu que: «a cualquiera le resultará evidente que nadie puede imponerme contra mi voluntad que altere esa rutina: un tercero no puede dormirme con un somnífero y, aprovechando esa situación, afeitarme la barba (en invierno) ni tampoco administrarme en el rostro un potente crecepelo (en verano). De, igual manera, el Estado tampoco está legitimado para obligar por decreto a que todos los varones lleven barba o, al contrario, a que ninguno la lleve» ${ }^{19}$. Pero esta afirmación no resulta, del todo, valida en todos los contextos, más en los tiempos que vivimos donde la «imagen» que se proyecta al exterior ha sufrido una transformación de tal calibre en apenas una veintena de años, que lo que antes eran usos sociales sobre indumentaria consolidados, ahora se ponen constantemente en tela de juicio.

$19 \quad$ Ibídem, p. 248. 
Sea como fuere, en algunos casos determinadas características físicas forman parte de la imagen de determinados personajes, que los hacen reconocibles en su entorno más inmediato. Por ejemplo, el uso continuo de un color en la indumentaria, la negativa a usar falda, etc., o el bigotillo y bombín de Charles Chaplin, los famosos los bigotes retorcidos de Salvador Dalí, la palestina de Yasir Arafat, el trasero de las Kardashian, los rizos de David Bisbal, el pelo despeinado y canoso de Albert Einstein, $\mathrm{y}$ así ad infinitum. El fundamento de este tipo de identificaciones debemos encontrarlo en el derecho a la "propia imagen» en la versión subjetiva, aunque, en algunas ocasiones, como el controvertido tema del hiyab esté, a juicio del Tribunal Europeo de Derechos Humanos de Estrasburgo, en la libertad religiosa como podría ocurrir con la exhibición visible de otros símbolos religiosos como la cruz latina, etc.; cuestión que, no obstante, excede del marco de nuestro estudio.

Aunque en la pasada década la práctica constitucional todavía defendía que el «que el derecho a la propia imagen no incluye, lo que, desde el punto de vista estrictamente gramatical o semántico, pudiera parecer: el derecho de cada uno a llevar el aspecto que estime oportuno; jurídicamente hablando $»^{20}$, como todo en la vida, los tiempos cambian, incluso podrá cambiar la jurisprudencia del Tribunal Constitucional por el surgimiento de nuevas realidades sociales. Es más, habría bases constitucionales para este cambio como podrían ser consideración conjunta o coordinada con el genérico derecho a la libertad ${ }^{21}$, que supondría «capacidad de autodeterminación en el aspecto físico de los seres humanos (...) que ello implica, a la libre configuración del aspecto físico» ${ }^{22}$, que comprendería el derecho a la propia apariencia que sería algo diferente del tradicional a la propia imagen.

Dice al respecto Gómez Corona que, «ciertamente, nadie puede poner en duda la existencia de un derecho a conformar nuestra apariencia física, aunque podamos discutir su fundamento preciso» ${ }^{23}$. Sin embargo, Pascual Medrano no comparte esta opinión que considera «el derecho a la propia apariencia nada tienen que ver con el derecho a la propia imagen» ${ }^{24}$. Así el derecho a la propia apariencia estaría más en la órbita de la manifestación o proyección del desarrollo de libre de la personalidad a que alude el art. $10 \mathrm{CE}$ y, obviamente de la dignidad de la persona reconocido en el art. 10 CE. Así, lo expuesto también por el Tribunal Constitucional en varias de sus SSTC como la 37/89, de 15 de febrero (Fj7), la 231/1988, de 2 de diciembre (Fj 3) o la 214/1991, de 11 de noviembre (Fj1). En el fondo, subyace la posibilidad de

20 PARDO FALCÓN, op. cit., p. 167.

21 También es discutible, pues se circunscribiría a la libertad deambulatoria (STC 53/2002, FJ 14) aunque la STC 29/2008, FJ 7 in fine, sin embargo, distingue entre libertad como valor superior del ordenamiento jurídico que supone que la persona «gozan de autonomía para elegir entre las diversas opciones vitales que se les presentan».

22 CUERDA RIEZU, op. cit., p. 249.

23 GÓMEZ CORONA, E. (2014), La propia imagen como categoría constitucional, Aranzadi, Navarra, p. 57.

24 PASCUAL MEDRANO, A. (2003), El derecho fundamental a la propia imagen fundamento, contenido, titularidad y límites, Aranzadi Thomson Reuters, Navarra, p. 65 (nota 6). 
reconocer a nivel constitucional un nuevo derecho, aún más concreto que el derecho a la «propia» imagen, o, al menos, que el Tribunal Constitucional opere claramente un cambio en su línea jurisprudencial que entendiese que, la referencia a la propia imagen del art. 18.1 CE ampararía un derecho a presentarse en la sociedad con aquella estética que uno estime más apropiada. Si bien, como todos los derechos, no sería absoluto, sino sometido a limitaciones y a la necesaria ponderación en determinados contextos más sensibles como el laboral. Esto es el juicio de razonabilidad, idoneidad y proporcionalidad en situaciones de conflicto, que suelen ser frecuentes en el ámbito laboral tanto en el sector público como en el sector privado.

La STC 70/1987, de 30 de octubre rechaza esta posibilidad que comentamos al desdecir la previa STC 99/1994, que trataba de abrir una pequeña vía para empezar a considerar al derecho a la propia imagen como «instrumento básico de identificación y proyección exterior» y la STC 120/1996, de 8 de julio, aunque, obviamente, evita reconocer esta segunda vertiente del derecho a la propia imagen. Resulta llamativo, pues, para Gómez Corona «pocas dudas caben de que a todos nos asiste el derecho a conformar nuestra propia apariencia física y que ella constituyese una manifestación de nuestra identidad personal, amparado por la Constitución. Ahora bien, esto no quiere decir, lógicamente, que se trate de derechos absolutos» ${ }^{25}$.

\subsection{La probibición de la reproducción de la imagen no consentida}

A finales del siglo xx que las Constituciones empiezan a admitir este derecho en los diferentes textos constitucionales. En España, en primer lugar, se discutió sobre si eran derechos autónomos; cuestión que quedó resuelta por la jurisprudencia del Tribunal Constitucional de reconocer la naturaleza autónoma de estas libertades, aunque aparezcan en el mismo precepto ${ }^{26}$, pues hay un contenido claramente diferente en el derecho a la propia imagen respecto del derecho al honor y a la intimidad personal y familiar, aunque el texto constitucional no permita deducirlo claramente, dado lo lacónico de su redacción ${ }^{27}$.

Desde entonces y hasta la fecha se ha explicado desde una visión clásica y reduccionista, que no distingue en su doble vertiente: «por un lado, la vertiente positiva, que consiste en atribuir a su titular la potestad de disponer de su imagen o cualquiera

25 GÓMEZ CORONA, op. cit., p. 58.

26 A este respecto: STC 156/200 y la 14/2003 (Fj 4): «ha de traerse a colación la doctrina de este Tribunal, según la cual los derechos al honor, a la intimidad personal y a la propia imagen, reconocidos en el art. 18.1 CE, a pesar de su estrecha relación en tanto que derechos de la personalidad, derivados de la dignidad humana y dirigidos a la protección del patrimonio moral de las personas, tienen, no obstante, un contenido propio y específico. Se trata, dicho con otras palabras, de derechos autónomos, de modo que, al tener cada uno de ellos su propia sustantividad, la apreciación de la vulneración de uno no conlleva necesariamente la vulneración de los demás (SSTC 81/2001, de 26 de marzo, FJ 2; 156/2001, de 2 de julio, FJ 3)».

27 Según STC 14/2003 se trata de tres derechos autónomos y sustantivos. 
de los elementos que componen su personalidad (la voz, el nombre, la cara, entre otros) y autorizar a terceros a obtener, reproducir y publicar la misma. Por otro lado, la vertiente negativa, que consiste en el derecho a prohibir la obtención, reproducción y publicación de la imagen por un tercero sin que haya mediado consentimiento del titular de esta». ${ }^{28}$ Por tanto, desde la óptica más objetivable del consentimiento frente a reproducciones de una imagen de la persona.

No me voy a extender en el comentario de esta cuestión porque el análisis de la misma, es más que sobrado por la doctrina constitucionalista. Entre otras, la STC de 26 de marzo de 2001 que establece que: «con la protección constitucional de la imagen se preserva no solo del evidente poder de decisión sobre los fines a los que haya de aplicarse las manifestaciones de la persona a través de su imagen (STC 117/1994) sino también una esfera personal, y en este sentido, privada de libre determinación». Así, el derecho a la propia imagen, en principio, se debe entender como salvaguarda de la proyección exterior de dicha imagen como medio de evitar injerencias no deseadas (STC 139/2001, de 18 de junio), además de una forma y manera de velar por una determinada imagen externa (STC 156/2001, de 2 de julio), a lo que se añade también la necesidad de preservar nuestra imagen pública (STC 81/2001, de 26 de marzo).

Por ello, es tanto un derecho de la personalidad como patrimonial por lo que tiene de explotación comercial, que cederá cuando «el titular del derecho hubiere prestado su consentimiento expreso» (art.2.2, LO 1/1982 de 5 de mayo). Es decir, será ilegítima la intromisión si «la captación, reproducción o publicación por fotografía, filme o cualquier otro procedimiento, de la imagen de una persona en lugares o momentos de su vida privada o fuera de ellos», salvo que esta sea de personas que ejerzan un cargo público o una profesión de notoriedad o proyección pública y la imagen se capte durante un acto público o en lugares abiertos al público (art. 8.2 LO 1/1982), u, obviamente, medie consentimiento.

Podríamos extendernos en el comentario de estas cuestiones, pero no es nuestro objetivo sino ahondar en la concepción constitucional de este derecho a una realidad, que ha superado y superará, con mucho y en breve tiempo, una explicación tan estricta.

\section{EL DERECHO A LA PROPIA IMAGEN Y LOS «CÓDIGOS DE INDUMENTARIA LABORAL: ¿VULNERACIÓN DEL ART. 14 O DEL 18.1 CE?}

\subsection{El estado de la cuestión en la jurisprudencia}

Será en el ámbito de las relaciones laborales donde aparecen las primeras limitaciones. Así, en el Estatuto de los Trabajadores respecto de las relativas a la higiene,

28 Entre otras: STS de 24 de julio de 2012 y autores como PERLA VELAOCHAGA, op. cit. pp. 31-39.

(C) UNED. Revista de Derecho Politico 
salud y seguridad y en los Convenios laborales respecto a determinados códigos de indumentaria o uniformidad. Sin embargo, el TC se ha resistido a interpretarlo desde el prisma del «derecho a la propia imagen» y lo ha analizado fundamentalmente de la posible discriminación injustificada y no razonable. La cuestión, por tanto, no se ha estudiado desde la dimensión de si se debe contemplar la libertad absoluta para vestir de determinada manera o si por el contrario puede estar sujeta a determinadas limitaciones en determinadas circunstancias donde puede observarse un conflicto de intereses: el empresarial o de marca y el del trabajador y sus derechos constitucionales reconocidos.

Diferenciemos, en primer lugar, entre el concepto social de dress code y el jurídico de «código de vestimenta». Sin embargo, no es exactamente lo mismo, porque el dress code alude a normas de uso social impuestas consuetudinariamente para acudir a determinados eventos, actos, espectáculos o reuniones sociales. Por tanto, el dress code básico se relacionaría con el traje o la ropa elegante para acudir a determinados eventos sociales. Estaríamos ante un conjunto de reglas sociales no escritas que concretan un atuendo que debe usar un grupo o personas en circunstancias específicas. Se trata de usos en eventos o actos sociales y el reproche será meramente social. Así, contaríamos como ejemplo de «dress code», el caso en el el tribunal juzgador dificultó que un opositor realizase la prueba sin chaqueta y corbata. El CGPJ ordenó que se le examinase otro tribunal diferente alegando que «el uso social como conducta generalizada y uniforme, ofrece manifestaciones carentes de trascendencia jurídica, de forma que su incumplimiento no acarrea responsabilidad jurídica alguna, sino, a lo sumo, cierta reprobación social (...) al impedir realizar este ejercicio al opositor, se estaba generando una responsabilidad con grave trascendencia jurídica, incluso, respecto del derecho fundamental al acceso a la función pública» ${ }^{29}$. En este caso, se entendió como un mero «convencionalismo social», si bien impedía el ejercicio de un derecho fundamental: el de acceso a la función pública (art. 23 CE).

Mientras que cuanto nos referimos a un «código de indumentaria» estamos ya en el ámbito de las relaciones jurídicas, esto es, se alude a determinado código obligatorio de indumentaria laboral. Así, lo usual es que estos códigos de vestimenta se apliquen respecto de los empleados de cara al público en el ámbito de la empresa privada, además, de otras particularidades de determinado funcionario del sector público. Se trataría, pues, como un supuesto de conflicto de derechos fundamentales: la libertad de empresa del art. $38 \mathrm{CE}$ que reconoce el poder directivo del empresario, siempre que ella sea razonable y los derechos que también asisten al trabajador. A saber: 10, $14,17,18$, etc. Estamos, pues, ante casos que se resuelve con la necesaria técnica de la «ponderación de derechos».

Estas limitaciones, se suelen fijar en el contrato laboral en el Convenio colectivo general de trabajo de que se trate, que es una norma jurídica que está a medio camino entre la Ley y el contrato, dado que, por un lado, es un acuerdo entre empleador y

29 Acuerdo del Pleno del CGPJ de 5 de abril de 2000. 
empleado, que obligan a las empresas que forman parte de su ámbito de aplicación como si se tratase de una norma con rango legal. Por esta especial posición tienen un expreso reconocimiento constitucional en el art. $36 \mathrm{CE} / 78$ y se integran en el resto de las normas del ordenamiento jurídico español y deben respetar todo lo contenido en la Norma constitucional, incluidos los derechos fundamentales. Así, «el Convenio colectivo es de obligado cumplimiento y los acuerdos y contratos individuales que puedan suscribir la empresa pueden mejorar su regulación, pero no empeorarla» ${ }^{30}$. Como ejemplo de Convenio colectivo podemos aportar el de la empresa The Disney Store Spain SL., publicado por Resolución de 4 de agosto de 2010, de la Dirección General de trabajo ${ }^{31}$, que regula esta cuestión en el art. 35 del siguiente modo: «El uniforme e Imagen: Entre los factores que contribuyen al logro de una alta calidad de servicio, la imagen ocupa un lugar importante. Por esta razón la presentación del personal debe ser en todo momento impecable. La normativa sobre uniformidad para todos los trabajadores de la Compañía se enmarca con carácter general en la capacidad discrecional de la empresa, por una parte, y de otra, en los criterios y objetivos de imagen establecidos por la Dirección. Esta normativa hace referencia tanto al diseño, confección, composición, mantenimiento y renovación de las diferentes dotaciones como el uso de las mismas, durante la prestación del trabajo. En anexo figuran las Normas Generales sobre el uso del uniforme y la imagen». Dicho Anexo es detalladísimo, entrando incluso a regular el vello facial y el tipo de pendientes que solo pueden ser: "planos o redondos, en oro, plata, diamante, perla o colores que coordinen con tu uniforme, no más grandes de $0.5 \mathrm{~cm}$. O los anillos que serán pequeños y alianzas solo uno por mano, como el reloj: discreto ${ }^{32}$.

Los tribunales, en general, «han entendido razonables tales obligaciones siempre que respondan a «consideraciones organizativas empresariales adoptadas con la finalidad de dar a la clienta una buena imagen ${ }^{33}$. Sin embargo, en algunos casos, estas exigencias pudieran ser excesivas. Por ejemplo, regular el color de la sombra de ojos o si el maquillaje debe ir en consonancia con el uniforme, como ocurrió con Eurohalding UTE, que, a juicio, del Tribunal Superior de Canarias, eran pautas desproporcionadas.

30 NOVOA MENDOZA, A. y MELGAREJO ORTUÑO, I. (2020), «El marco laboral del sector de la moda y la moda de lujo», en Fashion Law (Derecho de la Moda), dir. E. Ortega Burgos, Aranzadi. Navarra, p. 592.

31 BOE: 19 de agosto de 2010, núm. 201.

32 URL: https://boe.es/boe/dias/2010/08/19/pdfs/BOE-A-2010-13260.pdf. Es más, Walt Disney regula también la vestimenta de los clientes que acceden a sus parques: «Por motivos de seguridad, Euro Disney Associés S.C.A. se reserva el derecho de realizar una inspección visual de los efectos personales de los visitantes en la entrada de los parques y en el interior de sus recintos. Si el visitante se negara a la inspección, Euro Disney Associés S.C.A se reservará el derecho de impedir su acceso a los parques» (URL: https://docplayer.es/15796381-Reglamento-interno-de-los-parques-disney.html, fecha de consulta: 4 de marzo de 2021).

33 ARRÚE MENDIZABAL, M. (2019), El derecho a la propia imagen de los trabajadores, Aranzadi, p. 183 .

(C) UNED. Revista de Derecho Politico

N. ${ }^{\circ} 112$, septiembre-diciembre 2021, págs. 79-104 
No es raro, pues, que se acepten y establezcan determinadas normas, expresadas en «códigos empresariales» que pueden ser de dos tipos:

1. Códigos éticos o de conducta: estos se refieren a la obligación de respetar determinados principios que la empresa considera claves en sus relaciones con terceros y son obligaciones que nos son exigibles solo a los empleados y que pretenden evitar la mala imagen de la empresa a nivel nacional o internacional. Esto es lo que conocemos como «responsabilidad social corporativa» respecto de consumidores concienciados con cuestiones como el medio ambiente, el respeto de los derechos de los empleados, etc. Es decir, un conjunto de normas a seguir por la plantilla desde el punto de vista de las obligaciones de su contrato de trabajo y que observan una elevada tendencia a la proliferación y a la variedad, pues se entiende que las empresas podrían regular todas las materias que afectarían a sus empleados ${ }^{34}$, siempre claro está que no conculquen la legalidad vigente y el marco constitucional.

2. Códigos de vestimenta o uniformidad: por los que el empresario podría obligar a sus empleados a llevar cierta vestimenta en el trabajo; imposición que puede ser fuente de conflicto al conculcar derechos fundamentales, como el derecho a la imagen, a la seguridad y salud laboral, el derecho a la dignidad y el derecho a la no discriminación del trabajador por razón de género e, incluso, su derecho a la libertad religiosa.

Debe recordarse, por tanto, la legislación laboral. Así, el Estatuto de los Trabajadores ampara implícitamente el uso de códigos de vestimenta, y en concreto, su artículo 20. 2 y 3 que regula las facultades de dirección y control de la actividad laboral del siguiente modo:

«2. En el cumplimiento de la obligación de trabajar asumida en el contrato, el trabajador debe al empresario la diligencia y la colaboración en el trabajo que marquen las disposiciones legales, los convenios colectivos y las órdenes o instrucciones adoptadas por aquel en el ejercicio regular de sus facultades de dirección y, en su defecto, por los usos y costumbres $(\ldots)$

3. El empresario podrá adoptar las medidas que estime más oportunas de vigilancia y control para verificar el cumplimiento por el trabajador de sus obligaciones y deberes laborales, guardando en su adopción y aplicación la consideración debida a su dignidad y teniendo en cuenta, en su caso, la capacidad real de los trabajadores con discapacidad».

Esto significa que todo trabajador debe seguir las órdenes o instrucciones adoptadas por los empresarios siempre que estas normas de vestuario no vulneren ninguno de los derechos del trabajador recogidos en la Constitución española de 1978. Por

34 NOVOA MENDOZA y MELGAREJO ORTUÑO, op. cit., p. 595. 
tanto, la exigencia de que se use determinado atuendo durante la jornada laboral sería perfectamente constitucional, siempre que estos mandatos sean proporcionales y razonables, según el criterio de ponderación de derechos y libertades con los que opera el Tribunal Constitucional

Hay profesiones en que es necesario y obligatorio el uso de un uniforme concreto para el desempeño del trabajo por cuestiones de salud e higiene, cuyo coste suele asumir la propia empresa ${ }^{35}$, o para garantizar la prevención de riesgos laborales. Ej: los empleados de una pastelería y otros sectores de la alimentación, donde estaría justificado la prohibición de anillos. En caso de incumplimiento, este podrá ser sancionado disciplinariamente por la empresa o, dependiendo, de la gravedad, despedido de modo procedente, en el caso de negativa reiterada por parte del empleado a cumplir con dichas normas de vestuario, después de advertencia o apercibimiento.

Sin embargo, cualquier imposición que sea arbitraria, es decir, no se sustente sobre los criterios de la «razonabilidad» de la exigencia no estaría amparada y podría ser objeto de demanda ante la jurisdicción de lo social por parte del trabajador. Lo más recomendable, pues, es que estos códigos de vestimenta sean conocidos por el trabajador. Así, se debe comunicar fehacientemente en los que se les exige obligatoriamente utilizar o eliminar un cierto tipo de prendas. Por ello, o se incluyen en el contrato, o se comunican en un documento ad hoc redactado por la empresa o se les puede comunicar en cursos de formación, por ejemplo, en el caso, de trabajadores que manipulan alimentos. Así, v. gr. en el Corte Ingles para los empleados de pastelería y otros sectores alimenticios a los que se les exige falda o pantalón oscuro, camisa blanca, zapatos cerrados e igualmente, se prohíbe el uso de piercings, tatuajes visibles y anillos y otro tipo de joyería que pueda estar en contacto con los alimentos, en que también se les informa sobre situaciones de acoso.

En general, se suelen prohibir determinada indumentaria como las zapatillas de deporte (salvo en el caso de tiendas deportivas), camisetas de tirantes, etc. Además, se pueden establecer unas normas básicas de maquillaje y exigir que la barba esté bien cuidada, que el pelo no esté demasiado largo y que no se tiña de algún color demasiado llamativo, pero todo esto dependerá de la actividad que se desarrolle. Pensemos en el caso de determinadas peluquerías, donde los tintes llamativos podrían no ser un problema sino un reclamo comercial o barberías especializadas en hipsters.

En definitiva, estas normas de imagen y uniformidad deben aplicarse de forma proporcional, objetivamente justificada, flexible y razonable a la actividad. Recordemos que el art. 4, apartados c), d), y e) del Estatuto de los Trabajadores señala que los trabajadores tienen como derechos básicos, con el contenido y alcance que para cada uno de los mismos disponga su específica normativa, en los siguientes términos:

35 Aunque la STSJ de Andalucía (Málaga) 1769/2015, de 19 de noviembre de 2015 entendió que no era un uniforme propiamente dicho y que debía correr de parte del trabajador. 
«c) A no ser discriminados directa o indirectamente para el empleo, o una vez empleados, por razones de sexo, estado civil, edad dentro de los límites marcados por esta ley, origen racial o étnico, condición social, religión o convicciones, ideas políticas, orientación sexual, afiliación o no a un sindicato, así como por razón de lengua, dentro del Estado español $[\ldots]$

e) Al respeto de su intimidad y a la consideración debida a su dignidad, comprendida la protección frente al acoso por razón de origen racial o étnico, religión o convicciones, discapacidad, edad u orientación sexual, y frente al acoso sexual y al acoso por razón de sexo».

Encontramos, en este sentido, varios ejemplos: la STSJ Madrid, núm. 260/2015, Sala de lo Social, de 17 de marzo, que dirimía la imposición por la empresa a sus trabajadoras de la obligación de vestir uniforme compuesto de falda corta, blusa y calzado de tacón alto, cuando los trabajadores masculinos disponían de calzado plano, sus camisas no se transparentan y usaban pantalones ${ }^{36}$.

Otro fue el caso de las azafatas del AVE en que se requería la desestimación de la demanda por la Sala de lo Social de la Audiencia Nacional de 30 de septiembre de 1999, sobre el Reglamento de uniformidad del Convenio Colectivo de Renfe, en que se obligaba a sus empleadas a utilizar la falda como prenda de su uniforme en virtud de sus facultades organizativas previstas en los arts. 5 y 20 de la Ley del estatuto de los trabajadores (LET), alegando que el funcionamiento del AVE en 1992 suponía un atractivo emblemático de la empresa por lo que la era razonable exigir al personal que lo atiende una uniformidad especial y que el uso obligatorio de la falda en el ambiente social actual no era discriminatorio por razón de sexo, sino mera manifestación de moda o elegancia. El Tribunal Constitucional no falló sobre el caso por declarar extinguido el recurso de amparo por desaparición sobrevenida del objeto, al haberse producido la satisfacción extraprocesal de la pretensión por Acuerdo de 18 de mayo de 2004 entre el Ministerio de Fomento y el Sindicato Comisiones Obreras, como consecuencia de la decisión de la ministra, Magdalena Álvarez, asumida por ADIF, que dio instrucciones para que las azafatas del AVE pudiesen elegir entre falda o pantalón. Sin embargo, para el Alto Tribunal parecía que podría haber habido lugar a «la reparación de los derechos fundamentales que se denuncian vulnerados» tal y como veladamente apunta en el FJ 3 (STC 84/2006).

Un caso aún más curioso, por decirlo de algún modo, es el de las enfermeras del Hospital de San Rafael de Cádiz que se resolvió por sentencia del Tribunal Supremo de 19 de abril de 2011. En este supuesto, la empresa imponía solo a las trabajadoras a usar un uniforme que consistía en falda, delantal, cofia y medias como prenda obligatoria, sin poder utilizar el conocido como "pijama sanitario» que sí se reservaba a los varones. Se alegaba obviamente que esta decisión no era ajustada a derecho al vulnerar el derecho a no ser discriminadas por razón de sexo de las trabajadoras, a la

36 URL: https://www.iberley.es/jurisprudencia/sentencia-social-n-260-2015-tsj-madrid-sala-social-sec-3-rec-931-2014-17-03-2015-47294641, fecha de consulta: 17 de marzo de 2021. 
dignidad, intimidad personal y a la propia imagen. En este caso, la sentencia afirma: «la medida impuesta por la empresa en la forma en que ha quedado explicado en los anteriores fundamentos resulta discriminatoria por contener ilícita distinción entre hombres y mujeres y no permitir a éstas la utilización de la prenda de uniforme que utilizan los hombres en las mismas dependencias y con las mismas categorías, el pijama sanitario, lo que determina la necesidad de estimar el recurso en este punto [...] y declarar que la práctica empresarial (...) es contraria al principio de no discriminación por razón de sexo que se contiene en el artículo 14 de la Constitución Española» ${ }^{37}$.

También encontramos sentencias en sentido contrario, pero donde la discriminación alegada por el trabajador no parece lo suficientemente justificada. Así la sentencia del Tribunal Superior de Justicia de Madrid núm. 698/2007, Sala de lo Social, de 5 de noviembre, considera procedente el despido disciplinario de una trabajadora que reiteradamente acudía a trabajar con una camiseta deportiva «con número de dorsal, pantalones vaqueros y zapatillas de deportes, y por lo que la empresa ya le había sancionado en dos ocasiones anteriores». La empresa lo consideraba una vestimenta inadecuada para el desempeño de un puesto de comercial que suponía una atención directa al público. El tribunal resuelve, que, aunque no estuviese expresamente recogido en el contrato, es de «conocimiento común» que determinadas actividades laborales requieren una mínima corrección o pulcritud de la indumentaria conforme unas reglas de trato social comúnmente admitidas, que por ello se dan por supuestas sin necesidad de un acuerdo expreso, además de que considera el hecho de que había sido advertida en varias ocasiones.

Por otra parte, el derecho a la salud tampoco es alegable ante el Tribunal Constitucional, como sería pensable en el caso de uso obligado de tacones, porque después de la falda llegaron los tacones. Así, la STS de 23 de enero de 2001, que expone como, habiendo quedado acreditado que a las trabajadoras se les impone el uso de zapatos de tacón dentro de la misma categoría, esto resulta un componente de distinción vinculado al sexo de las trabajadoras y que supone una actitud empresarial que no resulta objetivamente justificada y por ello discriminatoria. Jurisprudencia que se reitera en la sentencia del 17 de marzo de 2015 del Tribunal Superior de Justicia de Madrid, que entendió que la medida empresarial de imponer a una trabajadora el uso de zapatos de tacón, cuando los empleados de género masculino utilizaban calzado plano, era discriminatorio, es decir, atentaba contra su derecho a la igualdad y no discriminación de una guía Patrimonio Nacional que se negó a ponerse uniforme y llevar tacones por considerarlo «sexista» e «inapropiado para su dignidad». Añade que, además, incluso, que el uso de tacones podría perjudicar la salud de las trabajadoras, traduciéndose en cansancio y en lesiones.

En 2017 la obligatoriedad del uso de los tacones centró el protagonismo, pues el Parlamento británico estaba estudiando la posibilidad de cambiar la Ley para conseguir

37 URL: https://www.poderjudicial.es/cgpj/es/Buscadores/?text=\&categoria=null, null,2398b5a0eee79210VgnVCM100000cb34e20aRCRD, fecha de consulta: 3 de abril de 2021.

(C) UNED. Revista de Derecho Politico 
prohibir la imposición de una vestimenta obligatoria para las mujeres en su lugar y, durante su tiempo de trabajo, que finalmente aprobó ${ }^{38}$. El caso se resumía en que Nicole Thorp fue contratada por una agencia de trabajo temporal para realizar las funciones de recepcionista en la empresa $\mathrm{PwC}$ en diciembre del año 2015, que en mayo de 2016 fue despedida por negarse a llevar zapatos de tacón, que eran las normas de vestimenta de la compañía y que ella había suscrito y aceptado al firmar el contrato de trabajo. Pero inició una recogida de firmas y el 6 de marzo de este año fue presentado el texto ante el Parlamento de Reino Unido para que se estudiase la posibilidad de prohibir la obligación de utilizar tacones altos en el lugar de trabajo.

Finalmente, se llegó a la conclusión de que las empresas británicas no podían obligar a que sus empleadas llevasen tacones altos y maquillarse, según el Comité Parlamentario de Igualdad para las Mujeres en Londres, pues vulneraba la Ley de Igualdad británica de 2010, que prohíbe este tipo de discriminación de género. Estamos hablando de la Equality Act 2010 (c. 15) 39 , cuyo art. 4 declara como protegidas las siguientes características: "age; disability; gender reassignment; marriage and civil partnership; pregnancy and maternity; race; religion or belief; sex or sexual orientation». El Código de Vestimenta de la empresa $\mathrm{PwC}$ es público y hay uno específico para mujeres ${ }^{40}$ se dice literalmente: «Zapatos: Los zapatos son el reflejo de la higiene y el cuidado personal. Es la prenda que define el grado de formalidad al vestir. (...) Son recomendables los zapatos de color negro, azul marino o café, de acuerdo con el color del traje sastre o que combinen con el mismo. La suela será de cuero, no de goma. Se sugiere tacón de $5 \mathrm{~cm}$. En caso de usar botas, deberán ser de los colores mencionados y la falda o vestido siempre tendrá que cubrir la parte superior de las mismas» ${ }^{41}$; un código muy detallado en cuestiones también como joyería, largo de la falda, cabello, maquillaje, manos: «El cuidado de las manos también es un aspecto fundamental para la imagen de la mujer. Es recomendable decorar las uñas con colores discretos, evitando llevarlas demasiado largas, así como portar exceso de anillos»; cuestión la del cuidado de que las manos, que no se detalla en el caso de los hombres, aunque, se dedica con especial hincapié en el tema de la corbata. En otras compañías, sin embargo, se apuesta por el «viernes casual» ${ }^{42}$.

38 Esta cuestión ya estaba resuelta en Columbia Británica, una provincia de Canadá, que había prohibido que se exigiese a las mujeres los tacones altos para ir a trabajar, no solo por ser discriminatorio sino también porque supone un riesgo de caídas y heridas, lo que compromete su seguridad en el centro de trabajo (URL: https://elpais.com/internacional/2017/04/08/actualidad/1491646477_046327. html, fecha de consulta: 17 de marzo de 2021).

39 URL: http://www.ilo.org/dyn/natlex/natlex4.detail?p_lang=es\&p_isn=88238

40 URL: Rec. 1851/2000, ECLI: ES:TS:2001:308, fecha de consulta: 1 de abril de 2021.

41 https://www.pwc.com/mx/es/spark/assets/codvestimujeres_pwc.pdf, fecha de consulta: 3 de marzo de 2021.

42 En 2019, Goldman Sachs anunció que la relajación del código de vestimenta de su compañía y convertirlo en «más casual y relajado». Si bien, en ciertos sectores empresariales, pongamos, por ejemplo, los grandes bufetes jurídicos, empresas de seguros o multinacionales comerciales de determinados 
Pero como ya decíamos, como el Legislativo del Reino Unido, los tribunales y el Tribunal Constitucional español lo resuelven desde el art. 14 CE por motivos de discriminación por razón de género o edad, principalmente. Ahora bien, la cuestión de verdadera enjundia, vendrán cuando haya que tratar otro tipo de situaciones que no se generen un trato discriminatorio sino de otro tipo de demandas que erigen su fundamento jurídico en el intrínseco derecho a la propia identidad; circunstancia esta que trataremos en otro momento. Así la ya 84/2006, de 27 de marzo, en que una de las partes alegaron no sufrir discriminación (art. 14 CE), así como de los derechos a la intimidad y a la propia imagen (art. 18.1 CE), mientras que en la respuesta del TC, a este se le olvida el derecho a la propia imagen al afirmar: «Es cierto que el sindicato recurrente entiende que, aun admitiendo que ya está permitido el uso del pantalón en el uniforme femenino, ello no debiera provocar la extinción de su recurso de amparo, en el que se suscita, sin duda, un relevante problema constitucional que tiene que ver con la dignidad de la persona y el libre desarrollo de la personalidad (art. 10.1 CE) así como con la igualdad y el derecho a la intimidad (arts. 14 y 18.1 CE)». También, incluso, la 23/2010, una de las últimas que lo analiza en que, a pesar de afirmar que «la inclusión de la propia imagen en el catálogo de derechos fundamentales especialmente protegidos por la Constitución está íntimamente vinculada a la garantía de la dignidad personal (STC 81/2001, de 26 de marzo, FJ 3) pues más allá de asegurar la individualidad se trata de garantizar así a la persona un trato que no contradiga su condición de ser racional igual y libre, capaz de determinar su conducta en relación consigo mismo y su entorno, esto es, una capacidad de «autodeterminación consciente y responsable de la propia vida» (SSTC 53/1985, de 11 de abril, FJ 8; 193/2003, de 27 de octubre, FJ 7)», vuelve a insistir, a renglón seguido en su dimensión objetiva al reconducirlo a que ello «implica también la interdicción de someter a la persona, contra su libertad, al tráfico comercial».

Pasemos al tema de la corbata que nos ha dejado alguna que otra anécdota en el ámbito político nacional, porque si hablamos de discriminación por razón de género en el ámbito laboral habrá que hablar también de la polémica corbata y traje de chaqueta con camisa de manga larga para los hombres en épocas cálidas. No en vano, no hace mucho esto supuso un enfrentamiento entre José Bono (en aquel momento, presidente de la Cámara Baja) y Miguel Sebastián (ministro Industria, Turismo y Comercio), curiosamente ambos del mismo partido político, y que, sin embargo, defendieron posiciones opuestas sobre en el uso de la corbata. Por un lado, Bono exigía que se cumpliesen normas de decoro en la vestimenta en la Cámara, y por otro, Sebastián, en aras del ahorro energético, apostaba por ganar en confort, quitarse la corbata en verano y reducir el frío del aire acondicionado, arguyendo que suponía un $7 \%$ de ahorro energético y que «la idea de quitarse la corbata no es de este ministro, sino de un Gobierno conservador, el de Japón en 2005 » ${ }^{43}$ y se siguió también en Portugal.

productos de cierto poder adquisitivo, la vestimenta de traje para los varones es una cuestión sencillamente innegociable.

43 URL: https://elpais.com/politica/2011/07/20/actualidad/1311152908_633039.html, fecha de consulta: 3 de marzo de 2021.

(C) UNED. Revista de Derecho Politico

N. ${ }^{\circ} 112$, septiembre-diciembre 2021, págs. 79-104 
Esta circunstancia, a los ojos de hoy en día, parece hasta un chiste, dados los cambios radicales que ha sufrido la vestimenta de los nuevos diputados, en aquel momento generó cierta controversia, que terminó por aprobar una Circular de la Secretaria General del Congreso de los Diputados sobre la vestimenta de sus señorías del siguiente tenor:

"La experiencia acumulada en los últimos tiempos en relación con la vestimenta adecuada para acceder a las dependencias del Congreso de los Diputados aconseja la aprobación de unos criterios, mínimos pero claros, que permitan compatibilizar la propia imagen que cada ciudadano quiera tener con el respeto a la dignidad y decoro de la Cámara, tal y como sucede en múltiples Instituciones públicas y privadas.

(...)

Por ello, esta Secretaría General, en uso de la habilitación concedida por la Mesa de la Cámara en su reunión del día 21 de junio de 2011, ha resuelto la fijación de los siguientes criterios:

1. El acceso y la circulación por los edificios del Congreso de los Diputados deberá efectuarse con la vestimenta adecuada al decoro exigible.

2. Queda probibido el acceso a las tribunas públicas durante la celebración de sesiones a quienes no vistan pantalón largo o falda. Igualmente, no se permitirá el acceso a los hombres en camisa sin mangas o camiseta de tirantes.

(...)

Las distintas unidades de la Secretaría General con competencias en la materia de acceso y circulación por las dependencias del Congreso de los Diputados vigilarán el cumplimiento de estos criterios e impedirán la entrada a quienes no se adecúen a los mismos»

Quizás por ello, Miguel Sebastián terminó poniéndose la corbata para comparecer en el Congreso. Este debate parece haberse relegado al olvido, pues no recuerdo que, al que fuese diputado y Vicepresidente del Gobierno, Pablo Iglesias, se le haya recordado la referida Circular de la Secretaria General del Congreso de los Diputados en su intervenciones en la Cámara. Curioso, cuanto menos.

\subsection{Imagen y proceso de selección}

Las mujeres son más escrutadas en cuanto a su imagen y su apariencia física no solo socialmente, sino también laboralmente, hasta el punto de que puede incluso reducir sus posibilidades laborales en trabajos de exposición pública. Ello sería lógico, si se aplicase también a los varones en la selección porque «los estudios del DR. Gordon Patzxer en torno a la cuestión del atractivo físico de las personas determinaron que los seres humanos tienden a responder más favorablemente de manera general a las personas que consideran más atractivas» ${ }^{44}$. Hay algo psicológico que nos induce a

44 Cit. BERNARD MONFERRER, E; ARDA, Z. y FERNÁNDEZ FERNÁNDEZ, C. (2012). «Publicidad de la industria de la belleza y mercado de trabajo: la belleza asociada al éxito profesional», 
pensar que las personas de mayor atractivo físico son más talentosas, más inteligentes y tienen más éxito. Esto en el caso de las mujeres es todavía más palpable, sobre todo en temas como cierto sobrepeso, etc. porque la industria publicitaria de la moda es tan potente que «impacta en el pensamiento social determinando un valor casi absoluto del lenguaje visual frente al oral, en donde el físico y la estética personal adquieren una importancia tan relevante que contribuye a propiciar la «tiranía de las apariencias» ${ }^{45}$; tiranía que más pronto que tarde también sufrirán también los hombres. Ello, porque hoy en día el éxito profesional pasa por centrarse en tres aspectos: juventud, delgadez y perfección corporal. Por mucho, que algunas empresas apuesten por campañas publicitarias como la de la «belleza real» o la actual, o el Proyecto \#Muéstranos de Dove, que ofrece una visión más inclusiva de la belleza, o Calvin Klein, que defiende la belleza individualizada.

\subsection{Análisis desde la perspectiva de género}

Pero sigamos con el tema del uso obligado de las faldas, que ni mucho menos está resuelto. Precisamente, porque ahora vamos a tratar el caso concreto de la «minifalda» que resulta no solo paradigmático, sino ciertamente desconcertante, pues si en un momento fue el símbolo de la liberación femenina, ahora puede ser justo todo lo contrario, es decir, motivo de discriminación por razón de género en el ámbito laboral, pero con unos matices tan sutiles que, a menudo, pueden pasar desapercibimos por el acostumbramiento social.

En la antigüedad la ropa era utilizada indistintamente por ambos sexos y no había disociación por géneros, sino por estatus social. Ya en el Medioevo se empieza a diferenciar por la longitud de las faldas y las togas, el uso de calzas, etc. Sin embargo, en la época moderna, es decir, desde los siglos XVI a XVIII fundamentalmente, es donde se empieza a separar con entidad y plena conciencia la ropa destinada al hombre y las prendas «apropiadas» para las mujeres, pues con ello se conformaba un nuevo orden social burgués que diferenciaba y remarcaba más aún la división entre lo público y lo privado y los roles asignados a cada uno de ellos. Así, «lo masculino fue identificado con lo universal, lo público y productivo y se opuso a lo femenino tanto en el ámbito particular, privado y reproductivo, excluyendo a las mujeres del espacio público» ${ }^{46}$, o, por lo menos de lo profesional. Parece querer perpetuar esta idea cuando las mujeres se han ido incorporando a ámbitos laborales o profesionales. Surgen una serie de controversias respecto de los estereotipos de la vestimenta femenina. Ello, porque, durante

en Investigación y género. Inseparables en el presente y en el futuro: IV Congreso Universitario Nacional "Investigación y Género», coord. por I. Vázquez Bermúdez, p. 170 (PATZER. G. (2008), Looks: Why The Matter More Than You Ever Imagined, Amazon, New York.

45 BERNARD MONFERRER y FERNÁNDEZ FERNÁNDEZ, op. cit., p. 172.

46 FACCIA, A. (2019). «Discursos sobre el cuerpo y la vestimenta u desigualdad de género», Cuadernos 76, núm. 20 (diciembre), p. 39.

(C) UNED. Revista de Derecho Politico 
tiempo el traje femenino fue configurado y pensado como algo complicado, pesado y poco práctico. De ahí, que, los primeros asuntos que trasladaron al ámbito de la judicatura por discriminación por razón de sexo en relación con las diferenciaciones en el ámbito de la vestimenta fue la falda o la minifalda, pues limita movimientos, son menos prácticas y obviamente más incómodas para el desarrollo de actividades laborales y, solo se exigían por una cuestión de gusto personal del empresario o por determinada estrategia de marketing empresarial como veremos después.

Como recuerda Mansilla Viedma: «en el epicentro, las mujeres consiguen primero la libertad de sus cuerpos, pura emancipación (...) aunque esa «inocente» rebeldía les hace tomar conciencia de las posibles consecuencias de su gesto. La causa de la primera vez es ahora el efecto y viceversa ${ }^{47}$. Así, hoy sobre la minifalda se observa el efecto radicalmente contrario, porque ha pasado de ser entendida como una prenda de liberación femenina a una posible prenda generadora de discriminación por razón de género en el ámbito laboral. Existen ámbitos profesionales, donde las mujeres se ven obligadas a usar minifalda, si bien no se acierta a explicar adecuadamente el porqué de la razonabilidad y proporcionalidad de esta exigencia. Ahora la lucha no es por llevar minifalda sino por la libertad de no llevarla en espacios laborales o deportivos donde la minifalda se utiliza como reclamo para el público masculino. Como por ejemplo las azafatas de congresos automovilísticos. Parece que no puede haber duda de que «una vestimenta que explotará la imagen femenina con connotaciones de carácter sexual, como norma general, sería una conducta claramente discriminatoria, además, mucho más rechazable por la importante afectación a la dignidad de las empleadas. La obligación de otro tipo de prendas como el uso de la falda, aunque sea decorosa, por las convicciones o ideas que expresa, también puede tener un componente de desvalor hacia las mujeres. La imposición de la falda refleja una concepción sesgadas de la moda y una interpretación sexista sobre el correcto estilo de vestir de la mujer, considerando que esta solo es elegante si utiliza esta prenda que expresa su condición femenina» ${ }^{48}$.

La polémica viene de atrás. Durante los años 60 y 70 las azafatas de vuelo estaban obligadas a cumplir unas medidas muy estrictas como estar solteras, ser bellas, delgadas, jóvenes e ir perfectamente maquilladas, peinadas y vestidas con un uniforme que consistía en una minifalda muy corta. La compañía parecía considerarlas como trabajadoras que publicitaban la compañía para la que trabajaban por su vestimenta e imagen física. Con los años, los uniformes se fueron haciendo más cómodos y adecuados a una sociedad en que la vestimenta y los estilos de vestir se han relajado y las fronteras entre géneros.

Sin embargo, en otros ámbitos laborales el proceso de igualación de la indumentaria está siendo algo más lento. En una oficina, por ejemplo, ambos géneros podrán usar

47 MANSILLA VIEDMA, P. (2017). «Sociología de la moda, un punto de vista privilegiado», Vínculos de Historia, núm. 6, p. 181.

48 ARRUE MENDIZABAL, op. cit., p. 200. 
traje de chaqueta, pero el corte, los colores, el calzado, los peinados son diferentes. Estas diferencias se notan aún más en épocas calurosas donde la indumentaria de las mujeres se relaja algo más que la de los hombres. Si bien, también es verdad que el aspecto físico de las mujeres es más comentado y los niveles de exigencia socio-laboral sobre su atuendo físico y su nivel de cuidado corporal en todas sus variables son mayores.

\section{CONCLUSIONES}

Como vemos, la jurisprudencia del Tribunal Constitucional, incluso la más reciente obvia referirse al derecho a la propia imagen en este tipo de casos. Si puede resolverlo como una cuestión de discriminación por razón de sexo, no lleva a cabo más análisis de la cuestión que meras referencias marginales que lo conectan con el libre desarrollo de la personalidad. Sin embargo, como ya hemos comentado no todo se reduce a estos casos aquí comentados. Llegará el día en que nuestro Tribunal Constitucional tendrá que asumir la tarea de decidir si en nuestro ordenamiento constitucional podría existir la posibilidad de amparar una nueva vertiente más subjetiva del derecho a la propia imagen, a modo de libertad de configuración de la propia apariencia o de identificación personal. Aquí ya no se tratará exclusivamente de si un trabajador se puede poner o no determinada prenda en el tiempo de su jornada laboral o de uniformes obligatorios que pueden atentar contra la dignidad del empleado, sino de cuestiones de mayor fondo del consabido artículo 14 CE. Hay casos en que este no será suficiente para determinar si ha habido vulneración o no del derecho. En estos casos, el Tribunal Constitucional, casi con toda seguridad se verá obligado a cambiar su doctrinal constitucional y hacer un esfuerzo interpretativo sobre apenas cinco palabras «derecho a la propia imagen» para adaptarlo a nuevas realidades sociales. Por lo que entraría dentro de uno de los supuestos de «especial trascendencia constitucional».

En los casos que hemos analizado, se trataban de despidos como consecuencia de una discriminación por razón de género o edad, por ello el recurso al artículo 14 era suficiente, pero cuando no hay un elemento de comparación, es decir, cuando al varón no se le impone una vestimenta más cómoda o no sexista, la referencia al artículo 14 resulta insuficiente. No se podrá llevar únicamente por la única vía de la discriminación, sino que los tribunales inferiores y el Alto Tribunal tendrán que decidir, que significa esto del derecho a la «propia» imagen e incardinarlo en las nuevas relaciones socio-laborales, máxime si dichos cambios en la apariencia podrían ser beneficiosos para la salud y, sin embargo, el empleador alegue que puede resultar desagradables a la vista de cierta clientela. Este es, pues, el nudo gordiano de la dimensión subjetiva del «derecho a la propia imagen» cuyo análisis hemos comenzado en estas páginas, pero conlleva más situaciones que cada día serán más frecuentes, pues los cambios en la sociedad actual avanzan a tal rapidez, que en breve se necesitará de una revisión y actualización de su contenido esencial. 
Title:

The right to one's own image in its subjective dimension and codes of occupational clothing

\section{Summary:}

I. Introduction, II. The classic characterization of the right to one's own image: A. Image and «own» image: conceptual differences, B. The prohibition of the reproduction of the non-consensual image, III. The right to one's own image and the «labor dress codes»: violation of art. 14 or 18.1 CE?: A. The state of the matter in jurisprudence: a. Image and selection process, $b$. Analysis from the gender perspective, IV. Conclusions.

\section{Resumen:}

En el presente paper se analiza el derecho a la propia imagen del art. 18.1 $\mathrm{CE} / 78$ desde una dimensión poco difundida. Se trataba de su dimensión como «derecho a la configuración de la propia apariencia», que todavía no ha sido asumida por el Tribunal Constitucional español que sigue resolviendo los conflictos laborales sobre los «códigos de indumentaria» desde la oposición del poder de dirección «razonable» de los empresarios con el art. $14 \mathrm{CE}$ que prohíbe todo tipo de discriminación, sin, apenas, aludir a la problemática intrínseca del derecho a la propia imagen que, a buen seguro, dará mucho que hablar en los próximos años.

\section{Abstract:}

In this paper the right to one's own image of art. 18.1 CE / 78 from a dimension little analyzed, its as «right to shape one's own appearance», which has not yet been assumed by the Spanish Constitutional Court, which continues to resolve labor disputes over «clothing codes» since the opposition of the «reasonable» management power of employers against art. 14 that forbidden all kinds of discrimination, hardly allude to the intrinsic problem of the right to one's own image that, surely, will give much to talk about in the coming years.

\section{Palabras clave:}

Propia imagen, código de indumentaria, configuración de la apariencia.

\section{Key words:}

Own image, dress code, appearance configuration. 